\title{
Peace research: the whys and the wherefores
}

Frank Barnaby, head of the Stockholm International Peace Research Institute (SIPRI), outlines the course being followed by military technology and offers his view on the role of peace research

"WITH the continuing technical progress and the current world-political constellation, it is highly probable that there will be an atomic world war before the end of this century." This statement was recently made by Professor Carl Friedrich von Weizsäcker, the West German physicist-philosopher, Director of the Max-Planck Institute in Munich, and author of the widely-discussed book The Relevance of Science. According to Professor von Weizsäcker a nuclear world war will probably be followed by the establishment of a world government which will ensure that no more nuclear world wars occur. In his view, then, it is likely to be the Third World War which will end all world wars.

Most students of military technology would agree that the probability of a general nuclear war is increasing-at least if only the consequences of advances in and the spread of military technology are taken into account. Three specific factors contribute to this conclusion. First, the nuclear arms race between the USA and the USSR could (and, therefore, probably will) eventually lead to a first-strike capability. This does not necessarily mean that one side will be able to destroy completely the other's capability to inflict casualties and damage in retaliation for a first-strike, but rather that this capability may be perceived to be sufficiently reduced to limit the casualties and damage to a level that might be considered acceptable for a given political goal. This level will depend on the recklessness and adventurousness of the political and military leaders in power at the time.

First-strike strategic nuclear weapons are likely to result from the improvement in accuracy of ballistic missiles. The accuracy of the current US Minuteman III land-based intercontinental ballistic missile, for example, is about 400 metres, at a range of about 13,000 kilometres. By the mid-1980s warheads with accuracies of about 30 metres may be available which, by any standards, will be first-strike weapons, even against small hardened targets. When it is remembered that the German V-2 missile could barely be depended on to hit London, the rate of progress which has been and which is still being made in missile technology will be realised. And similar progress has, of course, been made in many other areas of military technology.

If the limit has nearly been reached in the performance of strategic offensive missiles, there is still some way to go in strategic defensive systems. Much research is under way in defensive weapons against ballistic missiles and in anti-submarine warfare. A breakthrough in these areas, which can by no means be discounted, would be extremely dangerous for world security.

When the political and military leaders perceive a first-strike capability to be near they may intensify measures to defend the population, and to protect industry and vital plants from nuclear explosions. The effectiveness of these measures will of course be taken into account when assessing first-strike capabilities. That perceptions about "winning" a strategic nuclear war are likely to be proved wrong, if ever put to the test, is hardly a consolation, since civilisation as we know it will be

The second reason for concern is the worldwide spread of the capability to produce nuclear weapons, through the spread of peaceful nuclear technology, and of the technical knowledge and expertise required for nuclear-weapon production. It is extremely unlikely that any new international measures to establish a viable non-proliferation regime will succeed where the NonProliferation Treaty has failed. The most that can be hoped for is that measures-such as moratoria on the reprocessing of reactor fuel elements to remove the plutonium from them and on the large-scale construction of breeder reactors-will be taken to slow down the rate of proliferation.

The Achilles heel of the proliferation problem is that sufficient fissile material for a modest nuclear force could be obtained, by virtually any country wishing to do so, on a small scale, and secretly. The components for a small reactor able to produce enough plutonium for say two atomic hombs per year are available on the open market. And the reprocessing of a few tens of kilograms of plutonium annually could be done on a laboratory scale. The indigenous clandestine construction of a small uranium enrichment plant is also within the capabilities of many countries.

It is already hard to know for certain whether or not some countries have, or are producing, nuclear weapons (Israel, destroyed in the process. for example, has kept the world guessing for years), and this uncertainty will increase with time.

The third factor is the international trade in arms which is spreading the most sophisticated conventional arms worldwide. Since the October 1973 Middle East war this trade has increased at an unprecedented rate and is now virtually out of control. As a consequence, the arsenals of some Third World countries are more up-todate than are those of some industrialised countries. Many of the aircraft and missiles supplied to the Third World are capable of delivering nuclear weapons (on today's standards, even a crude nuclear weapon with an explosive power equivalent to that of 20,000 tons of TNT should weigh less than $1,000 \mathrm{~kg}$ ).

Some of the major recipients of arms become strongly bound to the supplier state, often to an extent hardly distinguishable from that of a close ally. This dependence is considerably heightened by the knowledge that in modern war munitions -- particularly anti-tank and anti-aircraft missilesare normally used at a very high rate. Victory may depend on the willingness of a great power to provide the massive quantities of replacements needed throughout the war. In this sense, the great power of ten becomes, implicitly or explicitly, the guarantor of the client state.

A war in, for example, an unstable region, involving one or more of these client states, could escalate from a conventional war to a limited nuclear war fought with the nuclear weapons of the local powers and then to the involvement of the great powers, committed to defend their clients---an involvement which might end in a general nuclear war. This end result is, of course, most likely to occur if one of the great powers perceives the chance of making a successful first-strike.

While not disputing the dangers inherent in unrestrained military technology, there are those who argue that increasing cooperation between states --in, for example, economic affairswill prevent the great powers from pursuing policies which lead to a general nuclear war. Whether or not tendencies for cooperation will, in the next two or three decades, outweigh those for confrontation is a matter of personal judgment. 1 find it hard to be optimistic given the rapid rate at which military technology advances and the relatively slow rate at which effective bonds between nation states are formed.

Taken together, the three factors 
will produce an extremely dangerous period in the not too distant future, unless steps are taken to prevent it. If, for example, a first-strike capability is developed it will take a very strongwilled and responsible leadership to resist arguments for its use. With so much at stake for us all, can we really afford to sit back and hope that the right men will be in power at the crucial times?

There is no reason why the current rate of progress in military research and development, the activity mainly responsible for progress in military technology, should not be sustained. In fact, because R\&D is the most difficult of all military activities to control, one can expect the rate of progress to continue to increase. Military technology has indeed come a very long way since the Second World War. Where will this technology take us by the end of this century? Scientists who ponder this question are generally doomsayers.

All of the ramifications of advances in military technology are known only to an extremely small group of people outside governments - to a few hundred scientists worldwide. It is a sobering thought that even within the world's governments at most a small handful of political leaders and their advisers are aware of the consequences of the onward rush of military technology. Under these circumstances and given the catastrophic nature of nuclear war, are the few scientists who do know the facts under a special obligation to publicise them?

The social responsibility of scientists has been much discussed over the past twenty years but inconclusively. There does, though, seem to be wide agreement that scientists do at least have a duty to inform non-specialists about any scientific developments (or the application of research results) which could lead to adverse social consequences. And the more dire the consequences then presumably the greater the duty to inform. But to whom should the information be addressed? In what form should it be presented? And how can its dissemination be best achieved?

These questions are particularly relevant to the Stockholm International Peace Research Institute (SIPRI), an independent institute established in 1966 and financed by the Swedish Parliament, which publishes factual studies on military technology, armaments, and disarmament (see Nature, 246, $397-400 ;$ 1973). During SIPRI's lifetime the situation in armaments and disarmament has changed considerably. Ten years ago there was still reason to hope that arms control negotiations would succeed in stopping the SovietAmerican arms race and lead, step-bystep, to significant disarmament. We now know differently. Throughout this period, the arms race has continued virtually unconstrained and the only weapons destroyed by international agreement have been biological weapons - weapons of little military interest.

Arms control may lead to the management of the arms race. Arms control may contribute to SovietAmerican détente. But, other than the actual negotiators and committed political leaders who soon develop a high level of 'professional optimism', few now believe that the arms control approach will actually lead to disarmament.

\section{'There is no reason why} the current rate of progress in military research and development, the activity mainly responsible for progress in military technology, should not be sustained. In fact, because $R$ \& D is the most difficult of all military activities to control, one can expect the rate of progress to continue to increase'

In my opinion, this lack of success, and the resultant ever-increasing probability of nuclear war, demands urgent action. Whereas in the mid-1960s it seemed that SIPRI's research should be aimed at the specialists advising those decision-makers and diplomats able to affect arms control negotiations, it is now clear that a much wider audience must be reached.

The political leaders of the great powers clearly lack the will to negotiate nuclear disarmament. There are two possible ways of applying the necessary pressure on these reluctant politicians. One is through public opinion, or at least the most influential sections of it, and the other is concerted action by the smaller countries.

SIPRI has neither the skills nor the resources needed to appeal directly to the public. But it can, and does, provide information in a form easily used by those who have - particularly journalists working for the press, radio and TV. SIPRI also makes sure that its material reaches the relevant authorities in the smaller powers.

A few of these powers-Canada, Mexico, the Netherlands, Sweden and Yugoslavia, among others-have a sizeable group of officials well trained in disarmament and related matters. But the bulk of the smaller countries do not. The one or two individuals in these countries dealing with the subject need information in a summarised and easily digested form which should also give a sense of the urgency of the current situation. An authoritative institute is able, and most would say has the duty, to provide this crucial service in addition to its various research publications.

All of this pre-supposes that farreaching disarmament (beginning with nuclear disarmament) can be directly negotiated in today's world of 150 or so states using the traditional methods of diplomacy and international law SIPRI believes this to be so. SIPRI also believes that unless this process is soon begun it may be too late to prevent a nuclear world war.

Some peace researchers, however, reiect these beliefs. They argue instead that conflict-leading eventually to general nuclear war--is inevitable because of the very nature of the present international system. The only way to prevent this, they say, is to change totally the system by developing entirely new international political and social institutions. In their view it is unrealistic to expect today's world to disarm, and even if it did the likelihood of nuclear war would remain. In my opinion, this approach is not only incorrect but dangerous. There is probably insufficient time to produce a new world order, even if such a thing were feasible. And there is the danger that too much emphasis on the inevitability of nuclear war may make it a self-fulfilling prophecy.

In summary, I believe that the dissemination of objective information on armaments and disarmament to specialists is still crucial but it is not enough. In addition, it is necessary to explain to non-specialists where military technology is taking us--particularly to the groups mentioned above--in a way which will stimulate their interest and hopefully provoke them to action. In this sense, SIPRI's work has become somewhat more 'political'.

The fear that the presentation of material in a brief and readable (even somewhat enlivened) form must damage the reputation for abjectivity of a research institute is, in my opinion, unfounded. When the need for political effectivity is urgent and great it is even defeatist. 